\title{
La Inteligencia Artificial
}

Mg. Ing. Luis Milla Lostaunau

Investigador colaborador

\section{RESUMEN}

Para entender la inteligencia hay que comprender cómo se adquiere, se representa y se almacena el conocimiento; cuánto tiempo dura; cómo se produce y se logra aprender el comportamiento inteligente; cómo se desarrollan y se usan las razones, las emociones y las escalas de prioridades; cómo las señales sensitivas son transformadas en símbolos; cómo se utilizan los símbolos para la aplicación de la lógica, para fundamentar sobre el pasado y planificar el futuro; y cómo la mecánica de la inteligencia produce los fenómenos de la ilusión, las creencias, las esperanzas, los sueños y los temores, la bondad y el amor.

Palabras clave: Máquinas, comportamiento, pensamiento, circuitos, lógicos, símbolos, ordenadores.

\begin{abstract}
For understand the intelligence it is important to comprehend how to acquire, represent and storage the knowledge, how many time last, how is produce and it to gain learn the behavior intelligent, how is development, and use reasons, emotions and priority scale, how the signs sensivites are changed in symbols; how utilize the symbols for the application of the logic, for to fundament on the last time and planning the future and how mechanic of intelligence produce the phenomenons of illusion, the belief, hopes, dreams, love and goodness.
\end{abstract}

\section{INTRODUCCIÓN}

La Inteligencia Artificial (IA) tiene por objeto el estudio del comportamiento inteligente en las máquinas. El mismo que supone percibir, razonar, aprender, comunicarse y actuar en entornos complejos. Una de las metas a largo plazo de la IA es el desarrollo de máquinas que puedan hacer todas esas cosas igual o quizás mejor que los humanos. Además, otra de las metas sería la de llegar a comprender este tipo de comportamiento, sea en las máquinas, en los animales o en los humanos. Por tanto, la IA persigue al mismo tiempo metas científicas y de ingeniería.

La IA estuvo siempre rodeada de controversias. La cuestión básica de la IA, ¿pueden pensar las máquinas?, es de interés de todos los profesionales y científicos. En un famoso artículo, Alan Tening, uno de los fundadores de la informática, expresó esta misma pregunta pero formulada en términos más adecuados para su comprobación empírica. La respuesta a la pregunta ¿pueden pensar las máquinas? depende de la definición que se le asigne a las palabras "máquinas" y "pensar". Tening pudo haber añadido que la respuesta depende también de cómo se define la palabra pueden.

Considerando primero la palabra "pueden”, ¿quiere decir que las máquinas pueden pensar ya ahora, o que algún día podrán pensar?, ¿queremos decir que las máquinas podrían ser capaces de pensar, en principio (incluso aunque nunca lleguemos a construir ninguno que lo haga), o lo que perseguimos es 
una implementación real de una máquina pensante? Esta cuestión es importante porque todavía no disponemos de ninguna máquina que tenga amplias habilidades pensantes.

La inteligencia de nivel humano, a escala real, podría ser demasiado compleja, o al menos demasiado dependiente de la fisiología humana, para existir fuera de su encarnación en seres inmersos en su entorno. La cuestión de que si alguna vez seamos capaces o no de construir máquinas pensantes de nivel humano, no admite aún una respuesta definitiva.

\section{LA MÁQUINA BIOLÓGICA}

Consideremos, por ejemplo, la palabra máquina. Para mucha gente, una máquina es todavía un artefacto rudo. La palabra evoca imágenes de engranajes rechinando, de chorros de vapor siseando y de piezas de acceso martilleando; ¿̨cómo podría llegar a pensar una cosa como esa? Sin embargo, hoy en día los ordenadores han ampliado la noción de lo que puede ser una máquina, y la comprensión de los mecanismos biológicos está creciendo aún más.

Si vemos un virus como el denominado bacterógrafo, en su cabeza contiene ADN vírico. Este virus es capaz de adherirse a la pared celular de una bacteria mediante las fibras de su cola, pinchar la pared e inyectar su $\mathrm{ADN}$ en ella. Este ADN hace que la bacteria fabrique millares de copias de cada una de las piezas del virus, después las piezas se ensamblan automáticamente, formando nuevos virus que salen de la bacteria para repetir el proceso. El ensamblaje completo se parece mucho al de las máquinas, por lo que podríamos asegurar que se trata de una máquina hecha de proteínas.

Aún no se conocen la función de los genomas completos de la bacteria
Haemophilus Influenczae Rd, 1743 genes; sin embargo, los científicos están comenzando a explicar el desarrollo y el funcionamiento de este organismo en los mismos términos en los que se explicaría para una máquina, muy compleja desde luego.

Hoy, tecnicas que son familiares a los informáticos, tales como el uso de cronogramas para los circuitos lógicos, están demostrando que son útiles para entender cómo los genes regulan los complejos procesos bioquímicos de un virus que infecta a bacterias. La secuenciación de los genomas completos de orros organismos, incluyendo el humano, está en curso. Conociendo estas marcas, ¿pensaremos que estos organismos bacterias, gusanos, moscas ratones, delfines, humanos, son como máquinas? ¡Si los humanos fuesen máquinas, se deduce que las máquinas pueden pensar! Tendríamos una demostración de su existencia. Lo que pasa es que no conocemos aún cómo funciona la máquina humana.

Sin embargo, aunque estuviéramos de acuerdo acerca de lo que es una máquina, el argumento sería rebatible. Una máquina hecha de proteínas puede pensar, una hecha de silicio, quizá no. John Scarle, conocido filósofo, cree que el pensamiento sólo puede ocurrir en máquinas muy especiales, máquinas vivientes hechas de proteínas.

\section{LA HIPÓTESIS DEL SISTEMA FÍSICO DE SÍMBOLOS DE NEWLL Y SIMON}

Esta hipótesis está en oposición directa a las creencias de Searle. La hipótesis establece que un sistema físico de símbolos dispone de los medios necesarios y suficientes para desarrollar una actividad general inteligente. De acuerdo con Newell y Simon, un sistema físico de símbolos es una máquina, tal como 
un ordenador digital, que es capaz de manipular datos, símbolos, sumar números, reordenar listas de símbolos por otros, etc.

Una parte importante de esta hipótesis es que no interesa de qué esté hecho el sistema físico de símbolos, la hipótesis es "neutral respecto al sustrato". Una entidad inteligente podría estar hecha de proteínas, de relés mecánicos, de transistores o de cualquier otra cosa, con tal que sea capaz de procesar símbolos.

Otros pensadores creen que no es realmente importante que las máquinas estén hechas de silicio o de proteínas, piensan que el comportamiento inteligente es, en su mayor parte, el resultado de lo que ellos llaman procesamiento subsimbólico, es decir, procesamiento de señales, no de símbolos.

Algunas hipótesis que se oyen a menudo son las siguientes:

- El cerebro procesa información en paralelo, los ordenadores convencionales lo hacen secuencialmente. Por tanto, se debe construir nuevas variedades de ordenadores paralelos para realizar progresos en la IA.

- La maquinaria computacional convencional está en la lógica binaria (verdadero o falso), por lo que los sistemas inteligentes tendrían que usar algún tipo de lógica borrosa.

- Las neuronas animales son mucho más complejas que simples conmutadores, los bloques constructivos básicos de los ordenadores actuales. Se necesitará neuronas artificiales realistas para construir máquinas inteligentes.

Quizá es demasiado pronto para alcanzar un consenso en el campo IA sobre el tipo de maquinaria requerida, aunque muchos investigadores aceptan la hipótesis del sistema físico de símbolos.
Actualmente, existen muchos programas de ordenadores capaces de realizar cosas realmente prodigiosas, incluyendo la planificación óptima de rutas aéreas para economizar combustible, la simulación global de condiciones meteorológicas, la planificación del uso de recursos en una factoría, etc.

\section{BREVE HISTORIA DE LA IA}

Cuando se desarrollaron los primeros ordenadores en las décadas de los años 40 y 50 , algunos investigadores escribieron programas que podían realizar tareas elementales de razonamiento.

En 1956 John Mc Carthy y Clude Shanmon coeditaron un volumen titulado Automata Studies. La mayoría de los artículos del volumen trataban sobre los fundamentos matemáticos de la teoría de autómatas, por lo que Mc Carthy, decepcionado, decidió poner el término Inteligencia Artificial y usarlo como título de una conferencia celebrada en Dartmonth en 1956.

El primer paso hacia la inteligencia artificial fue dado por Aristóteles (384-322 a. C.), cuando comenzó a explicar y a codificar ciertos estilos de razonamiento deductivo que él llamó silogismo.

Posteriormente, Ramón Lull (12351316), un místico y poeta catalán, construyó una máquina de engranajes, llamada Ars Magna, que supuestamente era capaz de responder a todas las preguntas. Pero hubieron científicos y matemáticos que perseguían la automatización del razonamiento, Martín Saydner atribuye a Gottfried Leibniz (16461716) el sueño de un álgebra universal, mediante la cual todo el conocimiento, incluyendo las verdades morales y metafísicas, pueda ser algún día representado en un único sistema deductivo. Leibniz llamó a su sistema Cálculo Filosófico o raciocinado, fue un 
sueño, que no pudo realizar por la distancia tecnológica de la época.

El programa al que se le da el mérito de ser el primero que demostró la importancia de recoger grandes cantidades de conocimiento específico del dominio fue DENDRAL, un sistema para predecir la estructura de moléculas orgánicas, a partir de su fórmula química y de su espectograma de masas (Teigenbunm, Buchanan y Lederberg, 1971 y Lindsay et al, 1980).

Una de las áreas en las que se ha realizado progresos sustanciales, al escalar el tamaño del problema, es el área de los juegos. El 11 de mayo de 1977, un programa, ordenador de IBM, denominado DEEP BLUE, consiguió vencer al entonces campeón mundial en ajedrez Gary Kasparov, por 3,5 a 2,5 en un encuentro de seis partidas. Este alto nivel de juego se ha conseguido gracias a la sinergia de sofisticados algoritmos de búsqueda, ordenadores de alta velocidad y hardware específico para el juego de ajedrez.

La inteligencia humana abarca muchas habilidades, incluyendo la de percibir $y$ analizar escenas visuales y la habilidad para entender o generar el lenguaje.

\section{CONCLUSIONES}

Tanto la aproximación ascendente de la IA, como la descendente, han estado inspiradas en estudios sobre comportamiento humano y animal. Los partidarios de la aproximación ascendente tienden a focalizar su atención en el comportamiento, que puede ser conseguido mediante el ensamblaje de elementos computacionales del tipo neuronal o de puertas lógicas, se han creado y utiliza- do diversos modelos computacionales de comportamiento animal, como los estudiados por los etólogos. Muchos de los modelos evolutivos y de los llamados modelos basados en comportamiento derivan de los modelos animales.

Los investigadores partidarios de la aproximación ascendente y los neurocientíficos han desarrollado modelos de redes neuronales que pretenden explicar ciertos fenómenos preceptuales y notas de los humanos, tales como los estudiados por los psicólogos.

Siempre podríamos adoptar un punto de vista, según el cual la forma en que los animales y los humanos alcanzan la inteligencia es completamente irrelevante para el problema ingenieril del diseño de máquinas inteligentes.

El diseño de un sistema inteligente debe olvidarse del problema de la obtención en el diseño del sistema correcto. Los problemas computacionales ponen un límite a aquellos que pueden ser conseguidos por un sistema inteligente.

\section{REFERENCIAS}

- Encyclopedia of Artificial Intelligence (Shapiro1992)

- The Hand Book of Artificial Intelligence [Ban y Feigenbaum 1984]

- Exploring Artificial Intelligence (Shrobe 1988]

- Journal of Artificial Intelligence Researh, Computational Intelligence.

- Journal of Experimental and Theoretical Artificial Intelligence Engineering Applications of Artificial Intelligence. 